CENTRE FOR FINANCE AND INVESTMENT

School of Management and Languages

Heriot-Watt University

\title{
What Style-Timing Skills do Mutual Fund “Stars” Possess?
}

\author{
Li-Wen Chen \\ National Chung Cheng University, Taiwan \\ Andrew Adams ${ }^{1}$ \\ Heriot-Watt University, UK \\ Richard Taffler \\ Manchester Business School, UK
}

June 2010

Discussion Paper 2010/01

\begin{abstract}
Kosowski, Timmermann, Wermers, and White (2006) find that certain growth-oriented fund managers have substantial skill but do not stipulate the particular skills that they possess. We examine in detail the style-timing abilities of 3,181 US growth-oriented equity mutual funds over the period from 1993 to 2006 . We find that an important contributor to the persistent abnormal returns reported by Kosowski et al. (2006) is growth timing, i.e. switching stocks along the value/growth continuum, and that this explains at least $45 \%$ of the abnormal returns reported. No other style-timing skills are observed. Our results also demonstrate that it is easy to misidentify growth timing as market timing.
\end{abstract}

Keywords: mutual fund performance; growth funds; timing skill.

JEL Classification: G23

${ }^{1}$ Corresponding author: Centre for Finance and Investment, School of Management and Languages, Heriot-Watt University, Edinburgh EH14 4AS. E-mail: A.T.Adams@hw.ac.uk. 


\section{What Style-Timing Skills do Mutual Fund “Stars” Possess?}

\section{INTRODUCTION}

Kosowski, Timmermann, Wermers, and White (2006) demonstrate that, in contrast to earlier work (e.g., Carhart (1997)), some growth-oriented mutual fund managers do earn positive abnormal returns due to genuine skill rather than good luck. ${ }^{2}$ However, they do not ask what skills these star fund managers possess. In this paper, we examine to what extent style-timing abilities can explain such superior performance, and the specific nature of any timing ability exhibited. We demonstrate that an important contributor to the persistent abnormal returns reported by Kosowski et al. (2006) is growth timing, i.e. switching along the value/growth continuum, and that this explains about half of the abnormal returns reported. We also find that only "growth" fund managers who invest primarily in growth stocks demonstrate such growth timing skill.

\footnotetext{
${ }^{2}$ Whereas Fama and French (2010) find little evidence of fund manager skill in general using a slightly different bootstrap simulation approach to Kosowski et al. (2006), they do not break their mutual funds down by style. On the other hand, Cuthbertson, Nitzsche, and O'Sullivan (2008), again employing a similar method to Kosowski et al. , demonstrate skill rather than luck among a relatively small number of top performing UK equity mutual funds.
} 
Fama (1972) suggests that mutual fund returns can be subdivided into two parts: return from stock selection and the return from market timing activity. The return from stock selection is defined as the difference between the return on the managed portfolio and the return on a naively selected portfolio with the same level of market risk. Market timing relates to the ability to forecast future market states and weight equity exposure accordingly. However, fund managers have other style timing opportunities apart from market timing, such as size timing, growth timing and momentum timing. In principle, size timers adjust exposure between small and large capitalization companies; growth timers modify exposure along the value/growth continuum; momentum timers choose between momentum investing and contrarian investing strategies. ${ }^{3}$ These four timing skills correspond to the four investment styles summarized by Carhart (1997). Broadly speaking, value stocks are stocks considered to be undervalued and growth stocks are those believed to offer above-average capital growth. The rationale for value investing is to evaluate the fundamental value of stocks, and then to buy-and-hold the under-priced stocks until their full value is realized. In contrast, the expectation of strong capital growth can push growth stock prices to relatively high levels in terms of price-to-earnings or price-to-book. In some

\footnotetext{
${ }^{3}$ Fama and French (1992) define growth (value) stocks as stocks with low (high) book-to-market ratio. Momentum investing is to buy high past-return stocks and sell low past-return stocks, while contrarian investing is the opposite strategy (Jegadeesh and Titman (1993) and Carhart (1997)).
} 
states of the market, value stocks tend to do well; in other states, it is growth stocks. If growth stocks are forecast as likely to go out-of-favor, shrewd growth-oriented fund managers will leave the market or reduce exposure to high growth stocks. If they leave the market, this is market timing activity; otherwise, it is growth timing. Our data show that, on average, growth-oriented funds invest over $90 \%$ of their assets in the stock market and adjust their market exposure only slightly. Indeed, equity fund managers do not normally claim to implement a market timing strategy. Furthermore, Wermers (1999) finds evidence of herding and positive-feedback trading by growth-oriented mutual fund managers. In other words, these managers tend to implement a momentum-based investment strategy, suggesting that they do not attempt momentum timing. We also find, using the S\&P Returns-Based Style Analysis, that more than 9 out of 10 of the growth-oriented funds in our sample invest primarily in large capitalization companies. ${ }^{4}$ Thus there is unlikely to be much evidence of size timing. To sum up, we would expect successful growth-oriented fund managers to exhibit growth timing ability. ${ }^{5}$

\footnotetext{
${ }^{4}$ Standard \& Poor's Returns-Based Style Analysis is derived from Sharpe (1992), and compares the historical performance of each fund with a series of index benchmarks to determine which benchmark (or combination of benchmarks) most closely describes the fund's actual returns.

${ }^{5}$ We recognize that fund managers change from time to time, and thus it is not necessarily correct to identify abnormal fund returns over time with the same fund manager. Nonetheless, we adopt the same approach as in extant work in considering funds and fund managers as synonymous. To the extent that this does not hold, our results must be considered as lower-bounded on this basis.
} 
Most studies, however, focus on market timing and do not reach a consistent conclusion. For example, Chang and Lewellen (1984), Lee and Rahman (1990), Busse (1999), Wermers (2000), Bollen and Busse (2001), Chen and Liang (2007), Jiang, Yao, and Yu (2007), and Swinkels and Tjong-A-Tjoe (2007) find evidence of successful market timing activity. Contrary evidence is provided by Treynor and Mazuy (1966), Henriksson (1984), Chen, Lee, Rahman and Chan (1992), Fletcher (1995), Jiang (2003), Byrne, Fletcher and Ntozi (2006) and Cuthbertson, Nitzsche and O'Sullivan (2010). In addition, Daniel, Grinblatt, Titman, and Wermers (1997) evaluate fund manager style timing skill in aggregate, but find no evidence of such ability in practice. Both Lu (2005) and Swinkels and Tjong-A-Tjoe (2007) consider market timing, size timing, growth timing and momentum timing separately. Lu (2005) finds evidence of size timing and growth timing skill, while Swinkels and Tjong-A-Tjoe (2007) find evidence of market timing, growth timing and momentum timing skill.

Methods employed to measure the timing skills of mutual fund managers can be classified into two types: return-based and holdings-based (Jiang et al., 2007). The return-based method compares mutual fund returns with relevant benchmarks to identify evidence that mutual fund managers are able successfully to forecast price movements (Treynor and Mazuy,1966; 
Henriksson and Merton, 1981; Lu, 2005; and Swinkels and Tjong-A-Tjoe, 2007). The holdings-based method analyses mutual fund portfolio holdings to estimate the returns earned by timing ability (Daniel et al., 1997; Jiang et al., 2007). Since this study explores the superior performance of fund managers identified by Kosowski et al. (2006) using Carhart's (1997) four-factor model, we also employ a Carhart-based model, i.e. return-based analysis, rather than a holdings-based analysis.

The most popular methods employed in return-based analyses are those of Treynor and Mazuy (1966) (TM) and Heriksson and Merton (1981) (HM) (Jiang, 2003). However, these parametric models have recently been criticized on the grounds (i) they do not distinguish between fund manger ability to time the market and the aggressiveness of their response and (ii) statistical robustness issues, in particular potential bias arising from heteroskedasticity and skewness (e.g. Jiang, 2003; Cuthbertson, et al, 2010). Non-parametric methods (e.g. Jiang, 2003; Abrevay and Jiang, 2005; Cuthbertson et al, 2010) have been developed as a result. However, there are serious difficulties in implementing such approaches when exploring different style-timing abilities as opposed to considering purely market timing skill as in most previous work. In addition, although like most previous studies we use the TM and HM methods, we employ the synthetic fund approach of Busse (1999) with associated bootstrap analysis (Kosowski et al, 2006) to 
overcome statistical robustness issues. We would also argue that in practice, an individual mutual fund investor is more concerned with overall fund performance than how this is decomposed between its manager's style-timing judgment and associated aggressiveness of response.

We use the factor timing models of $\mathrm{Lu}$ (2005) to examine four timing skills: growth timing, market timing, momentum timing, and size timing abilities. These models apply the TM and HM approaches to Carhart's (1997) four-factor model. In contrast to Swinkels and Tjong-A-Tjoe (2007), who use different timing models to measure the four timing abilities, we use integrated factor timing models to measure all four timing abilities at the same time. That is, we consider the correlations between the timing factors, which enables us to separate out the impact of each timing skill more precisely. Unlike most studies, including Lu (2005) and Jiang et al. (2007), we focus on superior performing growth-oriented fund managers, as in Kosowski et al. (2006). ${ }^{6}$

We examine the monthly net returns of 3,181 U.S. open-ended domestic growth-oriented equity mutual funds from January 1993 to December 2006. The test method is based on the idea that superior performing fund managers, who earn abnormal returns, have timing skill if they have an abnormally high probability of demonstrating timing ability. Our test results show that superior

${ }^{6}$ Chen, Jegadeesh, and Wermers (2000) also provide evidence that top performing funds tend to follow a 'growth' investment style. 
performing growth-oriented fund managers possess significant growth timing skill. In fact, growth timing accounts for at least $45 \%$ of the abnormal returns earned by these fund managers. There is no significant evidence, however, of successful market timing, size timing or momentum timing. We also conduct various sensitivity tests which suggest that the observed success in growth timing is not due to sampling variability, spurious statistics (Jagannathan and Korajczyk (1986) and Kosowski et al. (2006)) or chance.

The evidence also suggests that the use of growth timing skill is confined to those "growth" fund managers who actually invest primarily in growth stocks. According to the S\&P Returns-Based Style Analysis, 1,283 (40\%) of the 3,181 "growth-oriented" funds in our sample invest primarily in value stocks rather than growth stocks. ${ }^{7}$ We find little evidence of growth timing skill for such funds. In contrast, there is strong evidence of growth timing skill for superior performing funds invested mainly in growth stocks. Moreover, on studying our sample funds' investment objectives (which include aggressive growth, growth, growth-and-income and income-and-growth), we find that the more growth-oriented the investment objective, the

\footnotetext{
${ }^{7}$ We select our sample funds according to their investment objectives which are classified according to fund names, mandates, prospectuses, and/or the objectives claimed by mutual funds. Like Cooper, Gulen, and Rau (2005), who observe inconsistency between fund name and investment style, we find inconsistency between investment objective and style among our sample funds.
} 
stronger the evidence of growth timing ability.

Importantly, we also observe that growth timing skill persists. When we apply the method of Hendricks, Patel and Zeckhauser (1993), which is also used in Carhart (1997) and Kosowski et al. (2006), to test the persistence of growth timing ability, our results indicate that the top $10 \%$ of funds which demonstrate growth timing ability in the past three years also demonstrate the best growth timing ability in the following year. This confirms, as before, that superior performing fund managers possess growth timing skill.

Finally, we find that growth timing ability can be misidentified as market timing if the timing model focuses only on market timing skill (e.g., Treynor and Mazuy (1966), Henriksson and Merton (1981), Jiang et al. (2007), and Swinkels and Tjong-A-Tjoe (2007)). The factor timing models used in this study enable us to resolve this problem by considering correlations between the timing factors. Our results demonstrate growth timing skill, but not market, momentum or size-based timing skills.

To sum up, fund managers classified as having a growth investment objective by Standard \& Poor's should strive to buy or sell growth stocks in the knowledge that growth stocks go in and 
out of fashion. Our study demonstrates that this activity is growth timing rather than market timing. Growth timing skill is rewarded, with around half of the abnormal returns of superior performing growth-oriented funds attributable to successful growth timing activity. ${ }^{8}$ In addition, successful growth timing activity persists. It is likely that growth timing ability has been ignored in previous studies because growth timing ability is easily misidentified as market timing ability.

The rest of this paper is organized as follows. Section 2 explains the method adopted. Section 3 discusses the test data. Sections 4 and 5 report our empirical results. Section 6 is the conclusion.

\section{METHOD}

\section{(i) Style-Timing Models}

We extend the TM and HM methods, developed to measure market timing ability, to explore fund manager timing abilities with respect to Carhart's four factors. Market timing involves forecasting whether the stock market will produce better returns than investing in a risk-free asset, such as Treasury bills. It is a convex function of market excess return. TM depicts the convex function with a quadratic market excess return. The convex function of HM, however, is

\footnotetext{
${ }^{8}$ The remaining part of abnormal return is likely due to stock picking skill, other unidentified timing skills, or luck.
} 
the product of the market excess return and an indicator function which equals one if the market excess return is positive and zero otherwise.

Using Carhart (1997), the TM and HM methods can be extended to include the factors $S M B_{t}$, $H M L_{t}$, and $M O M_{t}$ in addition to $R M R F_{t}$, where $S M B_{t}, H M L_{t}$ and $M O M_{t}$ are month $t$ returns on value-weighted, zero-investment factor-mimicking portfolios for size, book-to-market equity, and one-year momentum in stock returns respectively, and $R M R F_{t}$ is month $t$ excess return on a value-weighted aggregate market proxy portfolio.

Our two factor timing models are thus:

a. CTM - the Carhart (1997) four-factor Treynor and Mazuy (1966) model:

$$
\begin{aligned}
r_{i, t}= & \alpha_{i}+\beta_{i} R M R F_{t}+s_{i} S M B_{t}+h_{i} H M L_{t}+p_{i} M O M_{t}+ \\
& \gamma_{1, i} R M R F_{t}^{2}+\gamma_{2, i} S M B_{t}^{2}+\gamma_{3, i} H M L_{t}^{2}+\gamma_{4, i} M O M_{t}^{2}+\varepsilon_{i, t}
\end{aligned}
$$


b. CHM - the Carhart (1997) four-factor Henriksson and Merton (1981) model:

$$
\begin{gathered}
r_{i, t}=\alpha_{i}+\beta_{i} R M R F_{t}+s_{i} S M B_{t}+h_{i} H M L_{t}+p_{i} M O M_{t}+ \\
\gamma_{1, i} R M R F_{t}^{*}+\gamma_{2, i} S M B_{t}^{*}+\gamma_{3, i} H M L_{t}^{*}+\gamma_{4, i} M O M_{t}^{*}+\varepsilon_{i, t} \\
R M R F_{t}^{*}=I\left\{R M R F_{t}>0\right\} R M R F_{t} \\
S M B_{t}^{*}=I\left\{S M B_{t}>0\right\} S M B_{t} \\
H M L_{t}^{*}=I\left\{H M L_{t}>0\right\} H M L_{t} \\
M O M_{t}^{*}=I\left\{M O M_{t}>0\right\} M O M_{t}
\end{gathered}
$$

where $\alpha_{i}$ is the abnormal returns of mutual fund $i ; r_{i, t}$ is the month $t$ excess return of mutual

fund $i$ (net return minus T-bill return); and $\left\{\gamma_{1, i}, \gamma_{2, i}, \gamma_{3, i}, \gamma_{4, i}\right\}$ measure market timing, size timing, growth timing, and momentum timing coefficients respectively. Significant positive $\gamma_{1, i}$ means successful timing between the stock market and cash/bonds, i.e. market timing. Similarly, significant positive $\gamma_{2, i}$ represents successful timing activity between small and big capitalization companies, i.e. size timing. Since growth (value) stocks tend to be stocks with lower (higher) than average book-to-market (B/M) ratios, Fama and French $(1992,2007)$ use book-to-market ratio to differentiate between growth and value stocks. ${ }^{9}$ Thus significant positive $\gamma_{3, i}$ captures timing on the basis of book-to-market ratio, termed growth timing in this paper.

Finally, since MOM represents the returns of past winners minus past losers, significant positive

\footnotetext{
${ }^{9}$ For example, both Fidelity Investments and Vanguard observe that growth stocks tend to be stocks with higher than average price-to-book (P/B) or price-to-earnings (P/E) ratios, and the characteristics of value stocks include relatively low P/B or P/E ratio. For more details, see https://www.fidelity.com/, and http://www.vanguard.com/ respectively.
} 
$\gamma_{4, i}$ indicates successful timing activity between momentum investing and contrarian investing strategies, i.e. momentum timing. We use the Kosowski et al. (2006) bootstrap method in place of the standard $t$-statistics to test the significance of coefficients. I\{condition\} is an indicator function that equals one if the condition is true, and zero otherwise. Other symbols are defined above.

Summary statistics for Carhart's (1997) four factors are reported in table 1 together with the equivalent for our CTM and CHM models. Variances of Carhart's four factors are relatively high compared with mean returns, and most of the correlations between factors or timing parameters are fairy low. This implies that multicollinearity does not substantially affect the estimated coefficients.

[INSERT TABLE 1 HERE]

(ii) Proportion Test

A proportion test is used to assess whether superior performing fund managers, who earn 
abnormal returns, possess timing skill. ${ }^{10}$ Since there are a large number $(3,181)$ of sample funds, even if no manager has timing skill, some funds may appear to demonstrate significant timing ability by chance (Lo and MacKinlay, 1990; Jiang et al., 2007), or due to option-like return distributions (Jagannathan and Korajczyk, 1986). In other words, we cannot judge whether a significantly positive timing coefficient is attributable to real skill, chance, or spurious statistics. To overcome such problems, we adopt the synthetic funds approach of Busse (1999) together with bootstrap methods to test whether superior performing fund managers have real timing skill. In the test procedure, we examine four fund groups: all funds, superior performing funds, all synthetic funds and superior performing synthetic funds. "All funds" is the group of 3,181 US growth-oriented funds in the sample. We follow the method of Busse (1999) to construct one corresponding synthetic fund for each sample fund. "Synthetic funds" are the artificial funds that exhibit the same time-series characteristics as the actual funds but do not incorporate any skill. "Superior performing (synthetic) funds" is the subgroup of all (synthetic) mutual funds that earn abnormal returns on the basis of the Carhart (1997) four-factor model.

\footnotetext{
${ }^{10}$ Although the phrase "fund managers" is used throughout, we focus on funds, as a group, not on any specific manager.
} 
The fundamental rationale underlying our proportion testing approach is that superior performing fund managers exhibit a particular style timing skill, such as market timing, if they have a significantly higher probability of demonstrating such timing ability than the other three fund groups: all sample funds, all synthetic funds, and superior performing synthetic funds. If the fund managers who earn significant abnormal returns manifest better market timing skill, for example, than all fund managers, there are four possible explanations. First, these superior performing fund managers have real market timing skill. Second, they do not have any market timing skill but average fund managers do even worse as regards market timing. Third, significant market timing ability arises because mutual fund returns are more or less option-like than the market proxy (Jagannathan and Korajczyk, 1986). Fourth, if the superior performance is due to good luck, and superior performing funds are the funds whose managers have better luck than others, this good luck may increase the probability of demonstrating market timing ability. Since all synthetic funds are random portfolios, the second and third reasons are rejected if superior performing fund managers have better market timing skill than synthetic funds. As regards the final reason, our superior performing synthetic funds have a higher probability of demonstrating market timing ability, similar to our superior performing fund managers. Therefore, this explanation is rejected if superior performing fund managers have a significantly higher probability of demonstrating market timing skill than the superior performing synthetic funds. If 
the last three reasons are rejected, superior performing fund managers must possess substantial market timing skill.

The whole test period is divided into sub-periods and each fund in each sub-period is defined as a fund instance. The first step in our proportion test is then to calculate the proportion of fund instances demonstrating each timing ability. If there are enough observations for a fund instance, we estimate the timing coefficient for the fund instance and apply the bootstrap method of Kosowski et al. (2006) to examine its significance. The total number of fund instances with enough observations and the number of the instances with significant positive timing ability are counted. The proportion demonstrating timing ability is then calculated as:

$$
\text { Proportion }=\frac{\text { Number of fund instances with significant positive timing ability }}{\text { Number of total fund instances with enough observations }}
$$

Our main tests follow the above procedure to compute the proportions under six different settings of sub-period lengths and minimum observation numbers for each of our four fund groups. The sub-period lengths used include 3, 5 and 9 years, and the sub-periods are established on $1^{\text {st }}$ January every year. For example, since the whole data period length is 14 years (January 1993 - December 2006), there are six sub-periods of 9-year length: 1993/01/01 - 2001/12/31, 
1994/01/01 - 2002/12/31 ... 1998/01/01 - 2006/12/31. In addition, we require there to be sufficient observations for the test, with the minimum observation numbers used being 36,60 , and 108 months. Therefore, there are six different settings for the sub-period length and the minimum observation number, i.e. (3 years, 36 months), (5 years, 36 months), (5 years, 60 months), (9 years, 36 months), (9 years, 60 months), and (9 years, 108 months). ${ }^{11}$

When comparing the proportions for two fund groups, we apply the permutation test principle to obtain the corresponding p-value of the statistical significance test of the null hypothesis that one proportion is less than or equal to another proportion. For example, we test the null hypothesis that superior performing fund managers have a lower proportion of fund instances demonstrating market timing ability than all synthetic funds. We assume that the numerator and denominator of equation (3) for superior performing funds are $N_{s}$ and $D_{s}$. The test procedure is as follows. First,

${ }^{11}$ We include only funds that have a minimum of 36 monthly net return observations giving enough degrees of freedom to generate sufficiently precise regression parameter estimates. Therefore, the minimum sub-period length is 3 years. In Kosowski et al. (2006), the minimum data requirement is 60 observations. Hence we also examine the test results with a 5-year sub-period. In addition, since the longer the sub-period length the fewer the fund instances, in order to examine the test results for a "long” sub-period, we choose a 9-year sub-period length under which the sub-period is long but fund instances do not decrease seriously. The 180 minimum observation requirement is used to examine the test results of long-lived funds. Concerning the start date of sub-periods, using $1^{\text {st }}$ January of every year allows us to establish the most sub-periods. In the sensitivity tests, we also examine the test results under other settings of sub-period lengths, minimum observation numbers and start dates of sub-periods. 
all fund instances of superior performing funds and all synthetic funds are pooled. We then randomly pick $D_{s}$ fund instances from the pooled fund instances, and count the number of fund instances with significant positive timing ability, denoted by $N_{p}$. The above process is repeated 1000 times, and $P$ is defined as the number of times that $N_{s}$ is greater than $N_{p}$. The p-value of the test on the null hypothesis is equal to $P / 1000$. If superior performing funds are compared with all funds, the test procedure is similar but we randomly pick the fund instances from all fund instances of all funds instead of the pooled fund instances because superior performing funds are a subset of all funds.

(iii) Bootstrap Analysis

The bootstrap method of Kosowski et al. (2006) is used in place of standard $t$-statistics to test for coefficient significance. Like Kosowski et al. (2006), we analyze the distribution of individual fund residuals generated by the commonly used Jensen (1968), Fama-French (1993), and Carhart (1997) performance models. We find that normality is rejected for over $36 \%$ of funds. ${ }^{12}$ This strong finding challenges the use of standard t- and F-tests for judgeing the significance of performance model coefficients. Kosowski et al. (2006) propose a baseline bootstrap method to

12 Specifically, normality is rejected for 55.5\%, 37.8\% and 36.4\% of funds based on the Jensen (1968), Fama-French (1993) and Carhart (1997) models respectively. Kosowski et al. (2006) find that normality is rejected for $48 \%$ of their funds when using the Carhart (1997) model and similar results are obtained with all the other models that they test. 
solve this problem and that method is also used in this study.

The basic concept of the bootstrap method is to reconstruct the distribution of the coefficients and then to use this distribution to assess their significance. The bootstrap method of Kosowski et al. (2006) first simulates fund excess returns under the null that the examined coefficient is zero. These excess returns are then used to estimate the bootstrapping coefficients. The bootstrapping coefficients with the same ranking in different bootstrap iterations are considered as the coefficient distribution of the ranking, which is used to assess the significance. To construct the distributions for one coefficient, 1,000 bootstrap iterations are required in this study.

For example, the distribution of alphas of Carhart's (1997) four-factor model for the top fund is constructed as being the distribution of the maximum alpha generated across all bootstrapping iterations. If it is found that the bootstrap iterations generate far fewer extreme positive values of alpha compared to those observed in the actual data, we conclude that high positive alphas are not only due to sampling variation (good luck) and that substantial skill exists. 


\section{MUTUAL FUND DATA}

We obtain monthly returns from the Center for Research in Security Prices (CRSP) mutual fund database. The CRSP database provides survivor-bias-free net returns for each share class of every US open-end mutual fund since January 1, 1962, and, from 1993 onwards, fund investment

objectives. Our sample contains fund-level monthly net returns for 3,181 US open-end growth-oriented domestic equity funds that existed for at least a portion of the period from January 1993 to December 2006. It consists of Equity Aggressive Growth funds (150), Equity Growth funds (1,956), Equity Growth-and-Income funds (856) and Equity Income-and-Growth funds (219). The final database contains 330,188 fund-level monthly net returns. ${ }^{13}$

Our sample funds are separately classified by the Standard \& Poor's (S\&P) Returns-Based Style

13 According to the CRSP database, 10,493 domestic equity mutual funds existed during our test period. Thus, our sample accounts for $30.31 \%(=3,181 / 10,493)$ of all equity funds. The sample of Kosowski et al. (2006) consists of 2,118 US growth-oriented equity mutual funds, which includes 285 aggressive growth funds, 1,227 growth funds, 396 growth-and-income funds, and 210 balanced or income funds. Although the test period of Kosowski et al. (2006), Jan. 1975 - Dec. 2002, is longer than ours, our mutual fund sample $(3,181)$ is much larger than their sample $(2,118)$ because many new mutual funds were created in more recent years. According to the "2008 Investment Company Fact Book” published by Investment Company Institute (http://www.ici.org/), there were 2,811 active mutual funds in 1995 but the number had increased to 12,021 by 2006. Our sample shows a similar trend. 
Analysis, as Growth funds (1,470), Blend funds (428), and Value funds $(1,283) .{ }^{14}$ Table 2 shows the distribution of sample funds in the cross-section classifications. ${ }^{15}$ The more growth-oriented the investment objective, the larger the proportion of funds classified as Growth funds. For example, 87\% (=131/150) of Equity Aggressive Growth funds are Growth funds while only 16\% (=134/856) of Equity Growth-and-Income funds are Growth funds. Table 2 also reveals that the more growth-oriented the investment objective (or style), the higher the average turnover ratio. For example, Equity Aggressive Growth funds have a higher average turnover ratio than Equity Growth-and-Income funds, and the average turnover ratio of Growth funds is higher than that of

14 S\&P develop their Returns-Based Style Analysis to estimate the types of stocks in which a mutual fund mainly invests according to its observed returns pattern. Growth (Value, Blend) funds are funds that primarily invest in growth (value, blend) stocks. S\&P defines growth stocks as stocks with a high 5-year earnings per share growth rate, high 5-year sales per share growth rate, and high 5-year internal growth rate (= ROE x Earnings Retention Rate), and value stocks as those with high book value to price ratio, high cash flow to price ratio, high sales to price ratio, and high dividend yield. Blend stocks lie between growth and value stocks. For more details, see "Standard \& Poor’s: S\&P U.S. Style Indices”, http://www2.standardandpoors.com/spf/pdf/index/SP_US_Style_Indices_Methodology_Web.pdf

15 It is possible to argue that Equity Income-and-Growth funds are not growth-oriented funds. Table 2 supports this proposition using the S\&P Returns-Based Style Analysis. Nevertheless, we still include them in our sample because we pick growth-oriented funds according to investment objective and "Equity Income-and-Growth" implies the possibility of growth stock investment. In fact, since Equity Income-and-Growth funds only account for a small proportion of our sample funds (7\%), whether or not these funds are included does not affect our results in unreported robustness tests. 
Value funds.

\section{[INSERT TABLE 2 HERE]}

Table 2 suggests that the investment objective claimed by mutual funds may not be consistent with their investment style in practice. For example, 27\% $(=522 / 1,956)$ of Equity Growth funds appear to invest in value stocks more than in growth stocks. Cooper, Gulen, and Rau (2005) also observe the inconsistency between fund name and investment style. They report that flows to a fund increase dramatically when the fund changes its name to look more (less) like the current positive (negative) return style. This is despite the fund not materially adjusting its holdings to reflect the style implied by the new name.

The S\&P Returns-Based Style Analysis shows that about $90 \%$ of our sample funds invest mainly in large capitalization firms, and the remaining $10 \%$ of funds belong to all capitalization funds. ${ }^{16}$

Mutual funds that invest mainly in middle or small capitalization firms are classified by S\&P as Equity Midcap, and Equity Small Company funds respectively, but not as growth-oriented funds.

\footnotetext{
${ }^{16}$ We also test the large capitalization funds and all capitalization funds separately. Both test results are consistent with the result for all sample funds.
} 
Since we do not know whether Equity Midcap and Equity Small Company funds also have a growth-oriented investment objective, we remove these from our sample to ensure all our funds are growth-oriented.

CRSP provides data on mutual funds' exposure to common stocks. The average market exposure of our growth-oriented funds over the 14-year sample period is $91.7 \%$ with an average fund standard deviation of 5.6\%. This suggests that any evidence of market timing ability in our sample will be muted at best.

\section{FUND MANAGERS' STYLE-TIMING SKILLS}

Before discussing the style-timing ability of mutual fund managers, we need to know whether style-timing is potentially profitable. Only then will mutual fund managers be motivated to implement a particular timing strategy. For example, in terms of the four Carhart (1997) factors we use, market timing, that is timing with respect to market excess return (RMRF), is potentially profitable if there are both periods of positive and periods of negative market excess returns. That is, sometimes equity market returns are higher than the risk-free return (one-month Treasury bill rate) and sometimes the risk-free return is higher than equity market returns. There are 168 
months in our test period from January 1993 to December 2006. In these 168 months, there are 107 positive RMRFs, 83 positive SMBs, 101 positive HMLs, and 105 positive MOMs. As regards 'turning points' when a factor changes from positive (negative) to negative (positive), there are 76 such points for RMRF, 83 for SMB, 78 for HML, and 76 for MOM. ${ }^{17}$ Therefore, timing with respect to all these factors is potentially profitable.

We conduct empirical tests to investigate market timing, size timing, growth timing and momentum timing skills. The first test is carried out on the whole sample to explore the timing skills of superior performing growth-oriented fund managers. We then carry out separate tests on different fund categories to explore the origin of the observed timing skill. Finally, we reveal a common problem that may exist in previous timing studies and show that our style-timing models are able to resolve this problem.

(i) The Style-Timing Skills of Superior Performing Growth-Oriented Fund Managers

Kosowski et al. (2006) reveal that certain growth-oriented fund managers possess genuine skill to earn abnormal returns. We therefore focus on growth-oriented fund managers who earn

${ }^{17}$ Data are collected from the website of Kenneth R. French: http://mba.tuck.dartmouth.edu/pages/faculty/ken.french/index.html 
abnormal returns and explore the source of their superior performance by extracting information about timing ability from the abnormal returns. ${ }^{18}$ Specifically, two factor timing models, the Carhart four-factor Treynor and Mazuy model (CTM), and the Carhart four-factor Henriksson and Merton model (CHM), are developed to measure the four timing abilities. We conduct the proportion tests introduced in section 2(ii) on the monthly data of our 3,181 US growth-oriented equity mutual funds from Jan. 1993 to Dec. 2006 to investigate what timing skills superior forming growth-oriented fund managers possess.

Panels A, B, C, and D of Table 3 report the test results for market timing, size timing, growth timing, and momentum timing abilities respectively. In each panel, the proportions of fund instances demonstrating timing ability are calculated for superior performing growth-oriented funds (Sup), all growth-oriented funds (All), superior performing synthetic funds (Ssy), and all synthetic funds (Asy) under six different settings of sub-period length and minimum observation number for our CTM and CHM factor timing models. Columns 7 to 9 of table 3 compare the proportion of fund instances for a superior performing growth-oriented fund manager demonstrating the respective timing skill with that of all growth-oriented fund managers,

\footnotetext{
18 In unreported work, we replicate the tests of Kosowski et al. (2006) on our data and also find strong evidence of superior performance and performance persistence among our sample funds.
} 
superior performing synthetic fund managers, and all synthetic fund managers. The last column

summarizes the results by reporting the significance level at which superior performing growth-oriented funds have a higher proportion of fund instances demonstrating timing ability than the other three fund groups.

[INSERT TABLE 3 HERE]

Table 3 provides strong evidence that superior performing growth-oriented fund managers possess growth timing skill (timing along the value/growth continuum). Panel C shows that, no matter what test setting and model are used, the proportions of fund instances of superior performing funds (Sup) demonstrating growth timing skill in column 3 are larger than those for the other three fund groups (all growth-oriented funds - All, all superior performing synthetic funds - Ssy, all synthetic funds - Asy) reported in columns 4-6. The last column of panel C shows that, at the 0.01 significance level, superior performing growth-oriented fund managers have a significantly higher proportion of fund instances demonstrating growth timing ability than the other three groups (All, Ssy and Asy). As discussed in section 2(ii) above, this abnormally high proportion of fund instances demonstrating growth timing ability suggests that superior performing growth-oriented fund managers possess growth timing skill. 
Importantly, the third column of panel C of table 3 shows that between $8 \%$ and $24 \%$ of fund instances of superior performing growth-oriented fund managers demonstrate growth timing ability. However, all growth-oriented funds, and random portfolios, such as all synthetic funds and superior performing synthetic funds, show a 3-13\% proportion of fund instances demonstrating growth timing ability (columns 4-6 of panel C, table 3). ${ }^{19}$ Thus we conclude that about $6-10 \%$ of superior performing growth-oriented funds have substantial growth timing skill.

No evidence, however, is found for the existence of market timing, size timing or momentum timing skills among superior performing growth-oriented funds. Table 3, panel A, which concerns market timing skill, shows in column 3 the proportion of fund instances of a superior performing growth-oriented fund manager demonstrating market timing skill and ranges from 0.82\% to $1.96 \%$, whereas the proportions for the other three fund groups (All, Ssy and Asy) in columns 4-6 are between $0.27 \%$ and $4.18 \%$. Therefore, superior performing growth-oriented fund managers do not have an abnormally high proportion of fund instances demonstrating

19 As shown in column 4 of panel C, the proportion of all fund instances ranges from $3.25 \%$ to $12.17 \%$. In fact, when using Carhart’s (1997) four-factor model, 2.57\% to 9.76\% of fund instances demonstrate a significant momentum (MOM) factor coefficient. Therefore, in our sample, the growth timing factor is of similar importance in explaining fund performance as Carhart’s (1997) momentum factor. 
market timing skill; hence there are no stars shown in the last column of panel A. Panels B and D provide similar results for size timing, and momentum timing respectively. That is, we cannot reject the possibility that the observed market timing, size timing, and momentum timing abilities of superior performing fund managers are due to good luck, or are spurious (Jagannathan and Korajczyk (1986)).

The results indicate the importance of growth timing activity for our growth-oriented funds. As shown in table 4, no matter what style timing model or test settings are used, our sample funds demonstrate obviously higher proportions $(5.87 \% \sim 12.17 \%)$ of significantly positive growth timing coefficients than the proportions of the other coefficients. In addition, there is a high positive proportion but low negative proportion only for growth timing coefficients, indicating the special growth timing ability of sample fund managers. The proportions for the other significant timing coefficients, whether positive or negative, are usually below 5.87\%. Although the proportion of significantly negative momentum timing coefficients is also high, the proportion test results provide no evidence of negative momentum timing ability.

[INSERT TABLE 4 HERE] 
Figure 1 shows that the observed growth timing skill accounts for at least $45 \%$ of abnormal returns earned by superior performing growth-oriented fund managers. There are 12,468 superior performing fund instances and their average Carhart alpha is 45 basis points per month (i.e. $5.54 \%$ per year). ${ }^{20}$ We find that superior performing random portfolios provide an average Carhart alpha of 34 basis points per month. Therefore, superior performing fund managers earn additional returns of 11 (=45-34) basis points per month (i.e. 1.32\% per year). Furthermore, we show that although superior performing synthetic funds maintain part of the growth timing ability of actual funds, they do not possess other timing skills. The average Carhart alpha of these superior performing synthetic funds is 39 basis points per month. Therefore, at least 5 (=39-34) basis points per month, i.e. $45 \%$ (=5b.p/11b.p) of abnormal returns, are attributable to the observed growth timing skill.

\section{[INSERT FIGURE 1 HERE]}

\footnotetext{
${ }^{20}$ As discussed in Section 2(ii), the sub-period lengths used in the tests include 3, 5 and 9 years, and hence there are 12, 10 and 6 sub-periods respectively over our 14-year test period from Jan. 1993 - Dec. 2006. Theoretically, since there are 3,181 funds in our sample and there are $28(=12+10+6)$ sub-periods for each fund, there are at most 89,068 $(=3,181 * 28)$ fund instances. Since some funds do not exist for the whole test period or do not have enough observations to estimate Carhart’s (1997) alpha, we have only 71,604 fund instances in total. Accordingly, the proportion of fund instances demonstrating superior performing funds which produce significant positive Carhart's (1997) alpha is about $17.41 \%(=12,468 / 71,604)$.
} 


\section{(ii) The Style-Timing Skills of Different Fund Groups}

Table 2 shows that, according to S\&P Returns-Based Style Analysis, about 40\% of growth-oriented funds have value fund return characteristics. This enables us to test our expectation outlined in the introduction that successful growth stock investment requires growth timing skill but successful value stock investment does not. If funds that invest primarily in value stocks do not possess growth timing skill but the other funds which invest primarily in growth stocks do, then this is strong evidence in favor of our expectation. Specifically, we expect funds with a higher degree of growth-orientation in their investment objective to demonstrate more significant growth timing skill.

To explore the nature of fund manager timing skill, we group our funds into seven categories defined according to investment objective or S\&P Returns-Based Style Analysis, and test each group separately for evidence of timing ability. Specifically, we divide our sample funds by investment objective into Equity Aggressive Growth funds (150), Equity Growth funds $(1,956)$, Equity Growth-and-Income funds (856) and Equity Income-and-Growth funds (219). In parallel, in line with the S\&P Returns-Based Style Analysis, we also separately classify our sample funds into Growth funds $(1,470)$, Blend funds (428), and Value funds $(1,283)$. 
Our test results suggest that growth timing is a distinctive characteristic of successful growth stock investment. Table 5 reports the test results for the existence of market timing, size timing, growth timing, and momentum timing skills in the form of the significance level of rejecting the respective null hypothesis that the superior performing fund managers of each of the seven fund groups do not possess the corresponding timing skill. ${ }^{21}$ Considering first the results for the four investment objectives, we see that superior performing Equity Aggressive Growth fund managers and superior performing Equity Growth fund managers have highly significant growth timing ability. Superior performing Equity Growth-and-Income fund managers also have growth timing ability in some settings. However, superior performing Equity Income-and-Growth fund managers do not demonstrate growth timing ability but have size-timing ability in some settings.

The more growth-oriented the investment objective, the stronger the evidence of growth timing ability. On average, 17.39\% of superior performing Equity Aggressive Growth funds and 16.04\% of superior performing Equity Growth funds demonstrate significant growth timing ability. The proportion for superior performing Equity Growth-and-Income funds is 15.66\%, but for superior

21 Table 5 shows the test results based on the CTM model. In unreported tests, the same tests are also conducted based on the CHM model. Since the test results are very similar, we only report those of the CTM model. 
performing Equity Income-and-Growth funds it is only 3.25\%.

\section{[INSERT TABLE 5 HERE]}

Concerning the test results of the three groups classified by S\&P Returns-Based Style Analysis, if a fund is classified as a Growth (Value) fund, this means that, according to its returns, this fund seems to invest most of its assets in growth (value) stocks. A Blend fund stands between Value and Growth funds. Columns 7-9 of table 5 clearly show that superior performing Growth fund managers have highly significant growth timing ability, superior performing Blend fund managers also have growth timing ability in many settings, but there is little evidence of growth timing ability for Value funds.

Again, the more growth-oriented the investment style, the stronger the evidence of growth timing skill. On average, $17.81 \%$ of superior performing Growth funds and $16.35 \%$ of superior performing Blend funds demonstrate significant growth timing ability. Only $11.82 \%$ of superior performing Value funds demonstrate significant growth timing ability.

We also apply the method described at the end of section 4(i) to estimate the abnormal returns 
earned by the observed growth timing skill for the fund groups which demonstrate growth timing

skill. ${ }^{22}$ On average, the observed growth timing ability of superior performing Growth funds contributes 7 basis points of abnormal returns, while that of superior performing Blend funds contributes 5 basis points. In addition, there are 6, 6, and 4 basis points of abnormal returns earned by the observed growth timing skills of superior performing Equity Aggressive Growth, superior performing Equity Growth and superior performing Equity Growth-and-Income funds respectively. To sum up, these findings show that the more growth oriented the fund, the greater the abnormal returns earned by the observed growth timing skill.

(iii) Market Timing is Misidentified Growth Timing

Since market timing is the best known timing skill and timing models, such as TM and HM, are developed to measure market timing ability, most studies tend to focus on market timing and ignore other timing skills. Swinkels and Tjong-A-Tjoe (2007) discuss the other timing skills, but

${ }^{22}$ We also examine the fund groups which do not demonstrate growth timing skill. The size timing skill of superior performing Equity Income-and-Growth funds contributes 2 basis points of abnormal returns. There are 3 basis points of abnormal returns earned by the observed timing skills of superior performing Value funds. Although, according to the test results of section IV.A, these two fund groups “may” exhibit little size timing and growth timing skill, the 2 and 3 basis points of abnormal returns are likely to be due to these skills, as any potential stock selection ability is removed in the estimation process. Since evidence for the existence of size timing and growth timing skill of these two groups is weak, however, we do not consider that they have material timing skills. 
correlations between the timing skills are not considered. This can lead to false conclusions if other timing skills are misidentified as market timing skill.

To test whether considering each type of timing skill separately leads to potential misidentification problems, we repeat the method of section 4(i) with models in which only one timing ability is measured. For example, the following models are the single timing models used to measure only growth timing ability.

a. The Carhart (1997) four-factor Treynor and Mazuy (1966) growth timing (CTM_GT) model:

$$
r_{i, t}=\alpha_{i}+\beta_{i} R M R F_{t}+s_{i} S M B_{t}+h_{i} H M L_{t}+p_{i} M O M_{t}+\gamma_{i} H M L_{t}^{2}+\varepsilon_{i, t}
$$

b. The Carhart (1997) four-factor Henriksson and Merton (1981) growth timing (CHM_GT)

model:

$$
r_{i, t}=\alpha_{i}+\beta_{i} R M R F_{t}+s_{i} S M B_{t}+h_{i} H M L_{t}+p_{i} M O M_{t}+\gamma_{i} H M L_{t}^{*}+\varepsilon_{i, t}
$$

where $\gamma_{i}$ is the growth timing coefficient, and a positive $\gamma_{i}$ means that the mutual fund manager successfully times across the value/growth continuum; $H M L_{t}^{*}=I\left\{H M L_{t}>0\right\} H M L_{t}$, where $I\left\{H M L_{t}>0\right\}$ is an indicator function that equals one if $H M L_{t}$ is positive and zero 
otherwise.

In a similar way, if we replace the growth timing factors, i.e. $H M L_{t}^{2}$ and $H M L_{t}^{*}$, with market timing factors, i.e. $R M R F_{t}^{2}$ and $R M R F_{t}^{*}$, the revised single timing models are able to measure only market timing ability as in Swinkels and Tjong-A-Tjoe (2007). We repeat the proportion tests conducted in section 4(i) with these single timing models instead of our factor timing models.

Our test results reveal that superior performing growth-oriented fund managers appear to possess market timing and growth timing skills. However, if superior performing growth-oriented fund managers really possess market timing skill, we should have observed it in tables 3 and 4, but we do not. In fact, panels $\mathrm{B}$ and $\mathrm{C}$ of table 1 show a significant level of correlation between market timing and growth timing factors, so growth timing ability is likely to be misidentified as market timing ability if there is no specific growth timing factor in the timing model used.

\section{(iv) Sensitivity Analysis}

To ensure that our findings are not due to sampling variability and are not spurious, we conduct various sensitivity tests. First, we implement a robustness test which repeats the test of section 
4(i) but without extreme large or small fund returns. Since most monthly returns are within the range -0.2 to 0.2 , our robustness test uses fund returns between -0.2 and 0.2 . Second, to test whether our results are biased because of excluding short-lived funds, we vary the requirement to include short-lived funds that have at least 12 months and 24 months of observations. ${ }^{23}$ Specifically, tests are conducted with four different settings for sub-period length, and minimum number of observation months: (2 years, 12 months), (2 years, 24 months), (3 years, 12 months) and (3 years, 24 months).

Finally, we also examine whether our proportion test results are sensitive to the test settings and different test periods. There are three main parameters in the proportion tests: sub-period length, minimum observation number of months, and start dates of the sub-periods. In addition to the six settings of these three parameters, our sensitivity analysis repeats all the proportion tests under all the combinations of other parameters: 4, 6, 7, and 8-year sub-period lengths; 48, 72, 84, and 96 minimum number of monthly observations; sub-period start dates ranging from 1st February to 1st December. Moreover, analyses are conducted on six 9-year test periods rather than across

${ }^{23}$ Short-lived funds tend to generate more extreme timing estimates than long-lived funds. This leads to nontrivial heteroskedasticity in the cross-section of timing estimates. To correct for this effect, we impose a minimum of 36 observations in order to exclude short-lived funds. However, this minimum observation requirement may impose a survivorship bias on our results. 
the original whole 14-year test period, Jan. 1993 - Dec. 2006. The six test periods are Jan. 1993 - Dec. 2001, Jan. 1994 - Dec. 2002, Jan. 1995 - Dec. 2003, Jan.1996 - Dec. 2004, Jan. 1997 - Dec. 2005 and Jan. 1998 - Dec. 2006. We also conduct parallel tests on the periods before and after 2001 to explore whether the technology bubble impacts adversely on our results.

All these sensitivity test results indicate that our findings are robust to extreme returns, fund survivorship bias, different sub-periods, and different test settings. No formal results are reported but they are available on request.

\section{FUND MANAGER SKILL PERSISTENCE}

If fund managers have substantial skill to outperform the market, their superior performance should persist. Both Carhart (1997) and Kosowski et al. (2006) apply this concept to test whether fund manager superior performance is attributable to skill or good luck. We use this persistence test method to confirm that our results are attributable to skill. But unlike Carhart (1997) and Kosowski et al. (2006), we examine the persistence of growth timing skill $\left(\gamma_{i}\right)$ rather than fund performance $\left(\alpha_{i}\right)$. 
Specifically, to test whether growth fund managers who demonstrate growth timing skill in the past three years also continue to exhibit such skill in the following year, we sort our superior performing growth-oriented funds on January 1 each year (from 1996 until 2006) into decile portfolios based on the prior 3-year performance. Portfolios are subsequently held for 1 year. The sort index used in Carhart (1997) and Kosowski et al. (2006) is the alpha of Carhart's four-factor model. Since we have found no evidence for the existence of the other three timing skills, we focus only on growth timing and thus use the Carhart (1997) four-factor Treynor and Mazuy (1966) growth timing model (CTM_GT) and the Carhart (1997) four-factor Henriksson and Merton (1981) growth timing model (CHM_GT), equation (4) and (5) respectively of section 4(iii). We use the growth timing coefficients of CTM_GT and CHM_GT as the sort index to test for persistence of growth timing skill.

A bootstrap method is used to estimate the significance level of the timing coefficients of the portfolios. Like the method of Kosowski et al. (2006), portfolio excess returns are simulated under the null that the examined coefficient is zero, and are then used to estimate 1,000 bootstrapping coefficients for each portfolio. Different from Kosowski et al. (2006), we construct the coefficient distribution of a portfolio according to the bootstrapping coefficients of the portfolio, not based on the ranking among all portfolios. 
Management expenses but not sale charges are considered in the test procedure. We study whether the observed growth timing ability is persistent, not whether fund investors can profit from this measure. Management expenses, such as management and administrative charges, 12b-1 fees, and other operating costs, arise from the activity of fund managers, and are considered as part of fund performance. ${ }^{24}$ On the other hand, sale charges such as front-end or deferred loads and redemption fees, are due to the activity of fund investors and hence are not included in our analysis.

A minimum of 36 monthly net return observations are required for estimating growth timing coefficients. For funds with missing return data, observations from the 12 months preceding the 3-year window are added to obtain 36 observations. This means that funds with missing observations are not excluded. On average, there are 164 superior performing growth-oriented

\footnotetext{
${ }^{24}$ Mutual fund monthly returns are based on the change in fund net asset value (NAV) from which management and administrative charges, 12b-1 fees, and other costs are deducted. To control for the possibility that our results might be biased by funds trading off front-end load fees against higher 12b-1 fees, in unreported tests, we remove all 12b-1 fees from the calculation of mutual fund performance. However, this does not affect our results.
} 
funds examined every year during the test period. ${ }^{25}$ The test results show the performance of holding the ranked portfolios for 1 year. Performance here includes excess return $\left(r_{i, t}\right)$, and the $\alpha_{i}$ and $\gamma_{i}$ of the growth timing model, i.e. CTM_GT or CHM_GT.

The observed growth timing ability persists. Panels A and B of table 6 report our persistence test results using CTM_GT and CHM_GT respectively. In both panels, the top ranked portfolio has the highest growth timing coefficient and the lowest bootstrapped p-value. In other words, the fund managers who demonstrate top $10 \%$ growth timing skill among superior performing growth-oriented fund managers in the past three years also demonstrate the best growth timing skill in the following year. This finding is consistent with the results reported in section 4(i) that only the top decile of superior performing growth-oriented funds demonstrate growth timing skill, but additionally provides empirical evidence that the observed growth timing ability is persistent.

\section{[INSERT TABLE 6 HERE]}

In unreported work, we also apply the same persistence tests to subgroups of our sample, Equity

${ }^{25}$ On average, there are 1,573 growth-oriented funds examined every year during the test period, and 10\% $(=164 / 1,573)$ of them are superior performing growth-oriented funds which demonstrate significant positive Carhart (1997) alpha. 
Growth funds, Equity Growth-and-Income funds, Growth funds, and Value funds. ${ }^{26}$ Equity Growth funds and Growth funds exhibit strong persistence of growth timing ability, while Equity Growth-and-Income funds exhibit little. Value funds show no persistence of growth timing ability. These results are consistent with the results of proportion tests on the subgroups in prior sections and again suggest that growth timing skill is demonstrated only by successful fund managers who actually invest in growth stocks.

In summary, the persistence of the observed growth timing ability confirms that superior performing growth-oriented fund managers possess substantial growth timing skill. Both proportion and persistence tests provide strong evidence of growth timing skill. Observed growth timing skill, however, is only attributable to a small portion of growth-oriented fund managers. This finding is consistent with the Kosowski et al. (2006) result that a sizable minority of growth-oriented fund managers have the ability to earn abnormal returns.

\footnotetext{
${ }^{26}$ There are not sufficient funds to implement persistence tests for Equity Aggressive Growth funds, Equity Income-and-Growth funds, and Blend funds.
} 


\section{CONCLUSION}

Based on Carhart's (1997) four-factor model, Kosowski et al. (2006) show that certain growth-oriented fund managers demonstrate genuine skill in earning abnormal returns. We go further to explore the timing abilities behind these superior returns. We examine the monthly returns of 3,181 US growth-oriented funds over the period 1993 - 2006, collected from the CRSP survivor-bias-free mutual fund database. Two style-timing models are developed by applying the approach of Treynor and Mazuy (1966) and Henriksson and Merton (1981) to the Carhart (1997) four-factor model. We use these style-timing models to extract information about timing abilities from the abnormal returns earned by growth-oriented fund managers. Specifically, we are able to measure market timing, size timing (timing between small and big capitalization stocks), growth timing (timing across the value/growth continuum) and momentum timing (timing between momentum investing and contrarian investing strategies) skills.

Our results indicate that superior performing growth-oriented fund managers, who earn abnormal returns, have an abnormally high probability of demonstrating growth timing ability. Growth timing accounts for at least $45 \%$ of the abnormal returns earned by those top decile growth-oriented fund managers who demonstrate significant skill. In addition, our results 
indicate that the more growth oriented the fund, the greater the returns earned by the observed growth timing skill. In other words, growth timing skill is specific to those managers who invest primarily in growth stocks. Importantly, we also find that growth timing skill is persistent.

However, there is no evidence that superior performing growth-oriented fund managers possess market timing, size timing or momentum timing skill. All sample funds are "equity" funds which tend to remain fully invested. It is therefore not surprising to find no empirical support for the existence of market timing ability. Similarly, about $90 \%$ of the sample funds invest mainly in large capitalization stocks, so they are unlikely to demonstrate significant size timing ability. As regards momentum timing, our results are consistent with Wermers (1999) who finds evidence of fund manager herding and positive-feedback trading. Thus, growth-oriented fund managers are likely to adopt a momentum investing strategy and not engage significantly in momentum timing activity.

We also find that growth timing ability is likely to be misidentified as market timing ability if researchers focus only on market timing ability. The factor timing models used in this study enable us to distinguish growth timing ability from market timing ability. This misidentification problem turns out to be important but is ignored in previous studies. 
In summary, our study demonstrates that superior growth-oriented fund managers have growth timing rather than market or other timing abilities. We also reveal that growth timing accounts for about half (at least 45\%) of the abnormal returns earned by growth-oriented fund managers. So this skill is important in practice and worthy of further study. For example, how/why superior performing growth-oriented fund managers successfully time across the value/growth continuum is an interesting topic for further research. Fund portfolio holdings data will show how individual fund managers adjust their portfolios, and hence should enable us to understand better how their stock selection decisions lead to successful growth timing.

We focus only on fund manager outperformance in this paper. However, Carhart (1997), Kosowski et al. (2006), and Cuthbertson, Nitzsche and O'Sullivan (2008; 2010) among others, provide strong evidence of negative skill being demonstrated by a much larger group of managers in both US and UK equity mutual fund sectors. Explanations for this underperformance are limited. Studying the potential role of parallel perverse style-timing (dis)abilities in the understanding of such mutual fund underperformance would be another interesting development of the current work. 


\section{References}

Abrevay, J., and W. Jiang (2005), 'A Nonparametric Approach to Measuring and Testing Curvature,' Journal of Business \& Economic Statistics, 23, pp. 1-19.

Bollen, N. and J. Busse (2001), 'On the Timing Ability of Mutual Fund Managers,' Journal of Finance, Vol. 56, pp. 1075-94.

Busse, J. (1999), 'Volatility Timing in Mutual Funds: Evidence from Daily Returns,' Review of Financial Studies, Vol. 12, pp. 1009-41.

Byrne, A, J. Fletcher and P. Ntozi (2006), 'An Exploration of the Conditional Timing Performance of UK Unit Trusts,' Journal of Business Finance and Accounting, Vol. 33, pp. 816-38.

Carhart, M. (1997), 'On Persistence in Mutual Fund Performance,’ Journal of Finance, Vol. 52, pp. 57-82.

Chang, E. and W. Lewellen (1984), 'Market Timing and Mutual Fund Investment Performance,' Journal of Business, Vol. 57, pp. 57-72.

Chen, C., C. F. Lee, S. Rahman and A. Chan (1992), 'A Cross-Sectional Analysis of Mutual Funds' Market Timing and Security Selection Skill,' Journal of Business Finance \& Accounting, Vol. 19, pp. 659-75.

Chen, H-L, N. Jegadeesh and R. Wermers (2000), 'The Value of Active Mutual Fund 
Management: An Examination of the Stockholdings and Trades of Fund Managers,' Journal of Financial and Quantitative Analysis, Vol. 35, pp. 343-68.

Chen, Y. and B. Liang (2007), ‘Do Market Timing Hedge Funds Time the Market?’ Journal of Financial and Quantitative Analysis, Vol. 42, pp. 827-56.

Cooper, M., H. Gulen and P. R. Rau (2005), 'Changing Names with Style: Mutual Fund Name Changes and Their Effects on Fund Flows,' Journal of Finance, Vol. 60, pp. 2825-58.

Cuthbertson, K., D. Nitzsche, and N. O'Sullivan (2008), 'UK Mutual Fund Performance: Skill or Luck?,' Journal of Empirical Finance, Vol. 15, pp. 613-34.

Cuthbertson, K., D. Nitzsche and N. O'Sullivan (2010), 'The Market Timing Ability of UK Mutual Funds,' Journal of Business Finance \& Accounting, Vol. 37, pp. 270-89.

Daniel, K., M. Grinblatt, S. Titman and R. Wermers (1997), 'Measuring Mutual Fund Performance with Characteristic-Based Benchmarks,' Journal of Finance, Vol. 52, pp. 1035-58.

Fama, E (1972), ‘Components of Investment Performance,' Journal of Finance, Vol. 27, pp. $551-67$.

Fama, E. and K. French (1992), 'The Cross-Section of Expected Stock Returns,' Journal of Finance, Vol. 47, pp. 427-65. 
Fama, E. and K. French (1993), 'Common Risk Factors in the Returns on Bonds and Stocks,' Journal of Financial Economics, Vol. 33, pp. 3-56.

Fama, E. and K. French (2007), 'The Anatomy of Value and Growth Stock Returns,' Financial Analysts Journal, Vol. 63, pp. 44-54.

Fama, E. and K. French (2010), 'Luck versus Skill in the Cross-section of Mutual Fund Returns', Journal of Finance, forthcoming

Fletcher, J (1995), 'An Examination of the Selectivity and Market Timing Performance of UK Unit Trusts,' Journal of Business Finance and Accounting, Vol. 22, pp. 143-56.

Hendricks, D., J. Patel and R. Zeckhauser (1993), 'Hot Hands in Mutual Funds: Short-Run Persistence of Relative Performance, 1974-1988,' Journal of Finance, Vol. 48, pp. 93-130.

Henriksson, R. (1984), 'Market Timing and Mutual Fund Performance: An Empirical Investigation,' Journal of Business, Vol. 57, pp. 73-96.

Henriksson, R. and R. Merton (1981), 'On Market Timing and Investment Performance. II. Statistical Procedures for Testing Forecasting Skills,' Journal of Business, Vol. 54, pp. $513-33$.

Jagannathan, R. and R. Korajczyk (1986), 'Assessing the Market Timing Performance of Managed Portfolios,' Journal of Business, Vol. 59, pp. 217-35. 
Jiang, G., T. Yao and T. Yu (2007), 'Do Mutual Fund Time the Market? Evidence from Portfolio Holdings', Journal of Financial Economics, Vol. 86, pp. 724-58.

Jiang, W. (2003), ‘A Nonparametric Test of Market Timing,' Journal of Empirical Finance, Vol. 10, pp. 399-425.

Kao, G., L. Cheng and K. Chan (1998), 'International Mutual Fund Selectivity and Market Timing During Up and Down Market Conditions,' Financial Review, Vol. 33, pp. 127-44.

Kosowski, R., A. Timmermann, R. Wermers and H. White (2006), 'Can Mutual Fund 'Stars' Really Pick Stocks? New Evidence from a Bootstrap Analysis,' Journal of Finance, Vol. 61, pp. 2551-95.

Lee, C. and S. Rahman (1990), 'Market Timing, Selectivity, and Mutual Fund Performance: An Empirical Investigation,' Journal of Business, Vol. 63, pp. 261-78.

Lo, A. and A. C. MacKinlay (1990), 'Data-Snooping Biases in Tests of Financial Asset Pricing Models,' Review of Financial Studies, Vol. 3, pp. 431-67.

Lu, J. (2005), 'What is the Wind behind This Sail? Can Fund Managers Successfully Time Their Investment Styles?' Ph.D. Thesis (Cranfield School of Management).

Sharpe, W. (1992), 'Asset Allocation: Management Style and Performance Measurement', Journal of Portfolio Management, Vol. 18, pp. 7-19. 
Swinkels, L. and L. Tjong-A-Tjoe (2007), 'Can Mutual Funds Time Investment Styles?’ Journal of Asset Management, Vol. 8, pp. 123-32.

Treynor, J. and K. Mazuy (1966), ‘Can Mutual Funds Outguess the Market?’ Harvard Business Review, Vol. 44, pp. 131-36.

Wermers, R. (1999), 'Mutual Fund Herding and the Impact on Stock Prices,' Journal of Finance, Vol. 54, pp. 581-621.

Wermers, R. (2000), 'Mutual Fund Performance: An Empirical Decomposition into Stock-Picking Talent, Style, Transaction Costs, and Expenses’, Journal of Finance, Vol. 55, pp. 1655-95. 
Figure 1: Abnormal returns earned by the growth timing skill of superior performing growth-oriented fund managers

This figure illustrates the components of the average abnormal return, i.e. Carhart's alpha, earned by the three fund groups: superior performing growth-oriented funds, superior performing synthetic funds, and superior performing random portfolios. The abnormal returns earned by superior performing growth-oriented fund managers are attributable to fund managers' good luck, the growth timing skill observed in this study, and other unidentified skills. We apply the method of Busse (1999) to construct the synthetic funds according to our sample funds' exposures to growth and value stocks. Exposure is corrected once a year so the synthetic funds retain only part of the growth timing ability of the sample funds. Therefore, the abnormal returns demonstrated by superior performing synthetic funds could be attributable to good luck, and part of the growth timing ability of our sample funds. Since the random portfolios are constructed by randomly picked stocks, the abnormal returns demonstrated by superior performing random portfolios are completely attributable to good luck. The number of fund instances used to estimate the average abnormal return for each fund group is shown in parentheses. The unit of the abnormal return is basis point (b.p.) per month. The figure illustrates how at least 45\% (5b.p/11b.p) of abnormal returns earned by the superior performing funds is due to growth timing skill.

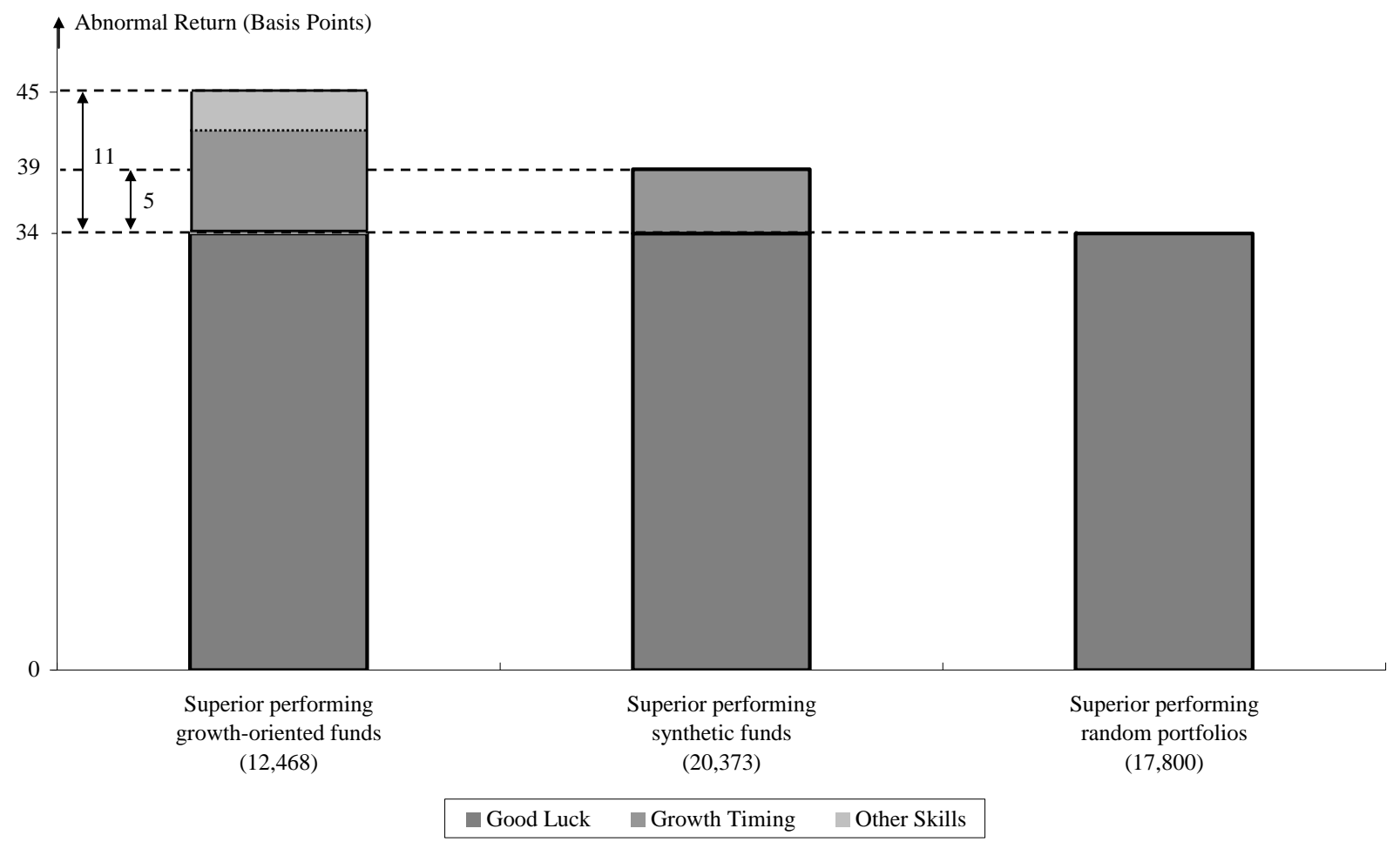


Table 1: Summary statistics for the parameters of our two factor timing models

This table reports monthly data summary statistics for the parameters of our two factor timing models, i.e. the Carhart (1997) four-factor Treynor and Mazuy (1966) model (CTM) and the Carhart (1997) four-factor Henriksson and Merton (1981) model (CHM), from Jan. 1993 - Dec. 2006. Both CTM and CHM models contain Carhart's (1997) four factors which include market excess return (RMRF), Fama and French's (1993) factor-mimicking portfolios for size (SMB) and book-to-market equity (HML), and Carhart's (1997) factor-mimicking portfolio for one-year return momentum (MOM). Carhart's four factors are collected from the website of Kenneth R. French, http://mba.tuck.dartmouth.edu/pages/faculty/ken.french/index.html. The CTM four timing parameters, i.e. $\mathrm{RMRF}^{2}, \mathrm{SMB}^{2}, \mathrm{HML}^{2}$, and $\mathrm{MOM}^{2}$, are the squares of Carhart's four factors. The CHM four timing parameters, i.e. RMRF ${ }^{*}, \mathrm{SMB}^{*}, \mathrm{HML}^{*}$, and $\mathrm{MOM}^{*}$, are equal to the respective Carhart factor when the factor $\geq 0$ and 0 otherwise. Columns 2 and 3 of panel A report the means and standard deviations of the time-series data for each of Carhart's four factors. The stars $\left(^{*}\right)$ denote the significance level of rejecting the hypothesis that the mean is equal to zero. The last four columns of panels $\mathrm{A}, \mathrm{B}$ and $\mathrm{C}$ respectively report the cross-correlations of Carhart's (1997) four factors, the CTM four timing parameters, and the CHM four timing parameters. $* * *, * *$, and $*$ represent significance levels of $0.01,0.05$, and 0.1 respectively.

\begin{tabular}{|c|c|c|c|c|c|c|}
\hline \multirow{2}{*}{$\begin{array}{l}\text { Factor or } \\
\text { Parameter }\end{array}$} & \multicolumn{2}{|c|}{ Monthly returns } & \multirow{2}{*}{\multicolumn{4}{|c|}{ Cross-correlations }} \\
\hline & Mean & Std. Dev. & & & & \\
\hline \multicolumn{7}{|c|}{ Panel A: Carhart's (1997) four factors } \\
\hline & & & RMRF & SMB & HML & PR1YR \\
\hline RMRF & $0.639 \% * *$ & $4.120 \%$ & 1.000 & & & \\
\hline SMB & $0.201 \%$ & $3.831 \%$ & 0.211 & 1.000 & & \\
\hline HML & $0.502 \% *$ & $3.524 \%$ & -0.522 & -0.494 & 1.000 & \\
\hline MOM & $0.808 \% * *$ & $5.000 \%$ & -0.195 & 0.180 & -0.037 & 1.000 \\
\hline \multicolumn{7}{|c|}{ Panel B: The CTM four timing parameters } \\
\hline & & & $\mathrm{RMRF}^{2}$ & $\mathrm{SMB}^{2}$ & $\mathrm{HML}^{2}$ & $\mathrm{MOM}^{2}$ \\
\hline $\mathrm{RMRF}^{2}$ & & & 1.000 & & & \\
\hline $\mathrm{SMB}^{2}$ & & & 0.051 & 1.000 & & \\
\hline $\mathrm{HML}^{2}$ & & & 0.338 & 0.538 & 1.000 & \\
\hline $\mathrm{MOM}^{2}$ & & & 0.187 & 0.472 & 0.438 & 1.000 \\
\hline \multicolumn{7}{|c|}{ Panel C: The CHM four timing parameters } \\
\hline & & & $\mathrm{RMRF}^{*}$ & $\mathrm{SMB}^{*}$ & $\mathrm{HML}^{*}$ & $\mathrm{MOM}^{*}$ \\
\hline $\mathrm{RMRF}^{*}$ & & & 1.000 & & & \\
\hline $\mathrm{SMB}^{*}$ & & & 0.156 & 1.000 & & \\
\hline $\mathrm{HML}^{*}$ & & & -0.349 & -0.202 & 1.000 & \\
\hline MOM $^{*}$ & & & 0.026 & 0.427 & 0.145 & 1.000 \\
\hline
\end{tabular}


Table 2: Number of sample funds and turnover ratios

This table reports summary statistics for 20 different classifications of our 3,181 sample funds. The classifications are: the four investment objectives i.e. Equity Aggressive Growth, Equity Growth, Equity Growth-and-Income, and Equity Income-and-Growth subdivided into the three S\&P Returns-Based styles i.e. Growth, Blend, and Value; the three S\&P Returns-Based styles without sub-division; and the whole sample. For each classification, panel A reports the number of funds and the corresponding percentage of all sample funds (in parentheses). Panel B reports the mean and standard deviation (in parentheses) of pooled annual turnover ratios.

\begin{tabular}{cccccc}
\hline \multirow{2}{*}{$\begin{array}{c}\text { S\&P } \\
\text { Returns-Based } \\
\text { Style }\end{array}$} & $\begin{array}{c}\text { Equity } \\
\text { Aggressive } \\
\text { Growth }\end{array}$ & $\begin{array}{c}\text { Equity } \\
\text { Growth }\end{array}$ & $\begin{array}{c}\text { Equity } \\
\text { Growth-and- } \\
\text { Income }\end{array}$ & $\begin{array}{c}\text { Equity } \\
\text { Income-and- } \\
\text { Growth }\end{array}$ & All \\
\hline \multirow{2}{*}{ Growth } & 131 & 1,205 & 134 & 0 & 1,470 \\
& $(4.12 \%)$ & $(37.88 \%)$ & $(4.21 \%)$ & $(0.00 \%)$ & $(46.21 \%)$ \\
Blend & 11 & 229 & 186 & 2 & 428 \\
& $(0.35 \%)$ & $(7.20 \%)$ & $(5.85 \%)$ & $(0.06 \%)$ & $(13.45 \%)$ \\
Value & 8 & 522 & 536 & 217 & 1,283 \\
& $(0.25 \%)$ & $(16.41 \%)$ & $(16.85 \%)$ & $(6.82 \%)$ & $(40.33 \%)$ \\
All & 150 & 1,956 & 856 & 219 & 3,181 \\
& $(4.72 \%)$ & $(61.49 \%)$ & $(26.91 \%)$ & $(6.88 \%)$ & $(100 \%)$ \\
\hline \multirow{2}{*}{ Growth } & 1.380 & 1.039 & 0.828 & -- & 1.053 \\
& $(1.538)$ & $(1.004)$ & $(0.623)$ & $(--)$ & $(1.047)$ \\
Blend & 2.144 & 0.808 & 0.725 & 0.413 & 0.797 \\
& $(1.442)$ & $(0.938)$ & $(0.688)$ & $(0.348)$ & $(0.871)$ \\
Value & 0.698 & 0.726 & 0.623 & 0.529 & 0.648 \\
& $(0.644)$ & $(0.617)$ & $(0.618)$ & $(0.400)$ & $(0.591)$ \\
All & 1.389 & 0.931 & 0.675 & 0.528 & 0.856 \\
& $(1.518)$ & $(0.923)$ & $(0.639)$ & $(0.400)$ & $(0.887)$ \\
\hline
\end{tabular}


Table 3: Proportion tests of fund manager timing skills: full sample

This table reports the results of proportion tests on monthly return data of 3,181 US growth-oriented equity mutual funds from Jan. 1993 to Dec. 2006. Panel A refers to market timing, panel B size timing, panel C growth timing, and panel D momentum timing abilities. Our proportion tests examine whether superior performing funds (Sup) have a higher proportion of fund instances demonstrating the respective timing ability than all mutual funds (All), superior performing synthetic funds (Ssy), or all synthetic funds (Asy). Column 1 reports the test setting of sub-period length (years) and minimum observation number (months). Column 2 shows the factor timing model used to measure timing ability, i.e. the Carhart (1997) four-factor Treynor and Mazuy (1966) model (CTM) or the Carhart (1997) four-factor Henriksson and Merton (1981) model (CHM). Columns 3 to 6 report the proportion (\%) of fund instances demonstrating the respective timing abilities for Sup, All, Ssy, and Asy. The following three columns report the p-values and significance of the permutation tests of the three hypotheses relating to the proportion of Sup $\leq$ the proportions of All, Ssy, or Asy respectively. The last column (Sig) summarizes the results of these permutation tests by reporting the minimum significance level of superior performing growth-oriented funds (Sup) having a higher proportion of fund instances demonstrating the respective timing ability than the other three fund groups. $* * *$, $* *$, and $*$ represent significance levels of $0.01,0.05$, and 0.1 respectively.

\begin{tabular}{|c|c|c|c|c|c|c|c|c|c|}
\hline Setting & Model & $\begin{array}{l}\text { Sup } \\
(\%)\end{array}$ & $\begin{array}{l}\text { All } \\
(\%)\end{array}$ & $\begin{array}{l}\text { Ssy } \\
(\%)\end{array}$ & $\begin{array}{l}\text { Asy } \\
(\%)\end{array}$ & Sup $\leq$ All & Sup $\leq$ Ssy & Sup $\leq$ Asy & Sig \\
\hline \multicolumn{10}{|c|}{ Panel A: Market Timing } \\
\hline \multirow{2}{*}{$(3,36)$} & CTM & 1.61 & 4.18 & 1.26 & 2.31 & 1.000 & 0.221 & 0.979 & \\
\hline & CHM & 1.96 & 3.91 & 1.31 & 2.48 & 1.000 & $0.069 *$ & 0.905 & \\
\hline \multirow{2}{*}{$(5,36)$} & CTM & 1.52 & 3.08 & 0.84 & 1.86 & 1.000 & $0.015 * *$ & 0.874 & \\
\hline & $\mathrm{CHM}$ & 1.26 & 2.25 & 1.18 & 2.08 & 1.000 & 0.442 & 0.998 & \\
\hline \multirow{2}{*}{$(5,60)$} & CTM & 1.26 & 2.21 & 0.80 & 1.35 & 1.000 & 0.118 & 0.587 & \\
\hline & $\mathrm{CHM}$ & 1.09 & 1.69 & 0.69 & 1.51 & 0.988 & 0.135 & 0.905 & \\
\hline \multirow{2}{*}{$(9,36)$} & CTM & 0.71 & 1.70 & 0.36 & 0.78 & 1.000 & $0.092 *$ & 0.607 & \\
\hline & $\mathrm{CHM}$ & 0.97 & 1.76 & 0.76 & 0.96 & 1.000 & 0.309 & 0.500 & \\
\hline \multirow{2}{*}{$(9,60)$} & CTM & 0.82 & 1.35 & 0.38 & 0.58 & 0.981 & $0.073 *$ & 0.163 & \\
\hline & CHM & 1.07 & 1.41 & 0.88 & 0.69 & 0.888 & 0.369 & $0.057^{*}$ & \\
\hline \multirow{2}{*}{$(9,108)$} & CTM & 0.95 & 0.58 & 0.36 & 0.27 & 0.124 & 0.120 & $0.002 * * *$ & \\
\hline & $\mathrm{CHM}$ & 0.95 & 0.64 & 1.07 & 0.35 & 0.149 & 0.500 & $0.010 * * *$ & \\
\hline
\end{tabular}


Table 3: Proportion tests of fund manager timing skills: full sample - continued

\begin{tabular}{|c|c|c|c|c|c|c|c|c|c|}
\hline Setting & Model & $\begin{array}{l}\text { Sup } \\
\text { (\%) }\end{array}$ & $\begin{array}{l}\text { All } \\
(\%)\end{array}$ & $\begin{array}{l}\text { Ssy } \\
(\%)\end{array}$ & $\begin{array}{l}\text { Asy } \\
(\%)\end{array}$ & Sup $\leq$ All & Sup $\leq$ Ssy & Sup $\leq$ Asy & Sig \\
\hline \multicolumn{10}{|c|}{ Panel B: Size Timing } \\
\hline \multirow{2}{*}{$(3,36)$} & CTM & 3.67 & 4.76 & 6.08 & 4.28 & 0.995 & 1.000 & 0.892 & \\
\hline & CHM & 3.37 & 4.59 & 3.12 & 2.74 & 0.997 & 0.352 & $0.055^{*}$ & \\
\hline \multirow{2}{*}{$(5,36)$} & CTM & 3.92 & 4.86 & 6.32 & 4.85 & 0.990 & 1.000 & 0.976 & \\
\hline & $\mathrm{CHM}$ & 3.33 & 3.64 & 2.57 & 2.21 & 0.804 & $0.071^{*}$ & $0.001^{* * *}$ & \\
\hline \multirow{2}{*}{$(5,60)$} & CTM & 4.12 & 3.57 & 6.29 & 3.60 & 0.111 & 0.998 & 0.141 & \\
\hline & $\mathrm{CHM}$ & 3.49 & 2.60 & 2.52 & 1.60 & $0.016 * *$ & $0.055^{*}$ & $0.000 * * *$ & $*$ \\
\hline \multirow{2}{*}{$(9,36)$} & CTM & 4.58 & 5.73 & 8.20 & 7.39 & 0.987 & 1.000 & 1.000 & \\
\hline & $\mathrm{CHM}$ & 2.50 & 4.08 & 2.24 & 2.93 & 1.000 & 0.335 & 0.862 & \\
\hline \multirow{2}{*}{$(9,60)$} & CTM & 4.27 & 4.69 & 8.22 & 6.06 & 0.782 & 1.000 & 0.999 & \\
\hline & $\mathrm{CHM}$ & 2.26 & 3.26 & 2.20 & 2.40 & 0.994 & 0.500 & 0.590 & \\
\hline \multirow{2}{*}{$(9,108)$} & CTM & 4.02 & 2.38 & 8.28 & 3.24 & $0.002 * * *$ & 1.000 & 0.114 & \\
\hline & CHM & 1.66 & 1.69 & 2.84 & 1.44 & 0.550 & 0.924 & 0.336 & \\
\hline \multicolumn{10}{|c|}{ Panel C: Growth timing } \\
\hline \multirow{2}{*}{$(3,36)$} & CTM & 10.05 & 6.41 & 4.67 & 4.00 & $0.000 * * *$ & $0.000 * * *$ & $0.000 * * *$ & $* * *$ \\
\hline & $\mathrm{CHM}$ & 8.59 & 5.87 & 4.52 & 3.70 & $0.000 * * *$ & $0.000 * * *$ & $0.000 * * *$ & $* * *$ \\
\hline \multirow{2}{*}{$(5,36)$} & CTM & 16.55 & 10.19 & 7.79 & 7.27 & $0.000 * * *$ & $0.000 * * *$ & $0.000 * * *$ & $* * *$ \\
\hline & $\mathrm{CHM}$ & 10.57 & 6.97 & 5.81 & 5.27 & $0.000 * * *$ & $0.000 * * *$ & $0.000 * * *$ & $* * *$ \\
\hline \multirow{2}{*}{$(5,60)$} & CTM & 16.41 & 7.58 & 7.49 & 5.42 & $0.000 * * *$ & $0.000 * * *$ & $0.000 * * *$ & $* * *$ \\
\hline & $\mathrm{CHM}$ & 10.23 & 5.16 & 5.60 & 3.85 & $0.000 * * *$ & $0.000 * * *$ & $0.000 * * *$ & $* * *$ \\
\hline \multirow{2}{*}{$(9,36)$} & CTM & 22.01 & 12.17 & 10.09 & 9.86 & $0.000 * * *$ & $0.000 * * *$ & $0.000 * * *$ & $* * *$ \\
\hline & $\mathrm{CHM}$ & 16.81 & 7.95 & 8.35 & 7.29 & $0.000 * * *$ & $0.000 * * *$ & $0.000 * * *$ & $* * *$ \\
\hline \multirow{2}{*}{$(9,60)$} & CTM & 22.54 & 9.88 & 10.23 & 7.99 & $0.000 * * *$ & $0.000 * * *$ & $0.000 * * *$ & $* * *$ \\
\hline & $\mathrm{CHM}$ & 17.39 & 6.45 & 8.66 & 5.93 & $0.000 * * *$ & $0.000 * * *$ & $0.000 * * *$ & $* * *$ \\
\hline \multirow{2}{*}{$(9,108)$} & CTM & 23.43 & 5.23 & 8.99 & 4.26 & $0.000 * * *$ & $0.000 * * *$ & $0.000 * * *$ & $* * *$ \\
\hline & $\mathrm{CHM}$ & 18.34 & 3.25 & 8.05 & 2.99 & $0.000 * * *$ & $0.000 * * *$ & $0.000 * * *$ & $* * *$ \\
\hline \multicolumn{10}{|c|}{ Panel D: Momentum timing } \\
\hline \multirow{2}{*}{$(3,36)$} & CTM & 2.61 & 2.76 & 5.98 & 4.35 & 0.658 & 1.000 & 1.000 & \\
\hline & $\mathrm{CHM}$ & 1.56 & 1.79 & 6.63 & 3.85 & 0.814 & 1.000 & 1.000 & \\
\hline \multirow{2}{*}{$(5,36)$} & CTM & 2.27 & 3.92 & 6.57 & 4.64 & 1.000 & 1.000 & 1.000 & \\
\hline & $\mathrm{CHM}$ & 1.56 & 2.11 & 7.37 & 4.45 & 0.981 & 1.000 & 1.000 & \\
\hline \multirow{2}{*}{$(5,60)$} & CTM & 2.23 & 2.93 & 6.63 & 3.42 & 0.962 & 1.000 & 0.997 & \\
\hline & $\mathrm{CHM}$ & 1.77 & 1.54 & 7.38 & 3.33 & 0.228 & 1.000 & 0.999 & \\
\hline \multirow{2}{*}{$(9,36)$} & CTM & 2.70 & 7.04 & 5.50 & 5.66 & 1.000 & 1.000 & 1.000 & \\
\hline & $\mathrm{CHM}$ & 0.82 & 3.19 & 6.06 & 4.62 & 1.000 & 1.000 & 1.000 & \\
\hline \multirow{2}{*}{$(9,60)$} & CTM & 2.57 & 5.79 & 5.96 & 4.64 & 1.000 & 1.000 & 1.000 & \\
\hline & $\mathrm{CHM}$ & 0.69 & 2.67 & 6.47 & 3.80 & 1.000 & 1.000 & 1.000 & \\
\hline \multirow{2}{*}{$(9,108)$} & CTM & 2.01 & 2.90 & 8.28 & 2.49 & 0.957 & 1.000 & 0.777 & \\
\hline & $\mathrm{CHM}$ & 0.24 & 1.29 & 8.99 & 2.18 & 1.000 & 1.000 & 1.000 & \\
\hline
\end{tabular}


Table 4: Summary statistics of fund instance coefficients of style timing models

This table reports the fractions of the significant timing coefficients of two style timing models of the 3,181 sample funds under six test settings. Columns 3-8 show the statistics for six test settings, in which the first number is sub-period length (years) and the second number is minimum observation number (months). The number in parentheses below each test setting is the number of fund instances. Panels A and B exhibit the statistics of the Carhart (1997) four-factor Treynor and Mazuy (1966) model and the Carhart (1997) four-factor Henriksson and Merton (1981) model respectively. Each panel shows the proportions (\%) of the corresponding timing coefficients that are significantly positive $(>0)$ and significantly negative $(<0)$ at the 0.01 significance level.

\begin{tabular}{|c|c|c|c|c|c|c|c|}
\hline & & $\begin{array}{c}3,36 \\
(18,474)\end{array}$ & $\begin{array}{c}5,36 \\
(18,331)\end{array}$ & $\begin{array}{c}5,60 \\
(12,476)\end{array}$ & $\begin{array}{c}9,36 \\
(14,429)\end{array}$ & $\begin{array}{c}9,60 \\
(10,599)\end{array}$ & $\begin{array}{c}9,108 \\
(4,650)\end{array}$ \\
\hline \multicolumn{8}{|c|}{ Panel A: The Carhart (1997) four-factor Treynor and Mazuy (1966) model } \\
\hline Market & $>0$ & 4.18 & 3.08 & 2.21 & 1.70 & 1.35 & 0.58 \\
\hline Timing & $<0$ & 2.83 & 2.39 & 2.25 & 2.62 & 2.39 & 2.53 \\
\hline Size & $>0$ & 4.76 & 4.86 & 3.57 & 5.73 & 4.69 & 2.38 \\
\hline Timing & $<0$ & 4.23 & 3.70 & 4.11 & 5.29 & 6.16 & 7.94 \\
\hline Growth & $>0$ & 6.41 & 10.19 & 7.58 & 12.17 & 9.88 & 5.23 \\
\hline Timing & $<0$ & 3.77 & 3.99 & 4.27 & 2.28 & 2.33 & 2.07 \\
\hline Momentum & $>0$ & 2.76 & 3.92 & 2.93 & 7.04 & 5.79 & 2.90 \\
\hline Timing & $<0$ & 4.74 & 6.34 & 6.48 & 8.38 & 9.12 & 9.29 \\
\hline \multicolumn{8}{|c|}{ Panel B: The Carhart (1997) four-factor Henriksson and Merton (1981) model } \\
\hline Market & $>0$ & 3.91 & 2.25 & 1.69 & 1.76 & 1.41 & 0.64 \\
\hline Timing & $<0$ & 2.24 & 1.09 & 0.94 & 1.07 & 0.74 & 0.51 \\
\hline Size & $>0$ & 4.59 & 3.64 & 2.6 & 4.08 & 3.26 & 1.69 \\
\hline Timing & $<0$ & 4.32 & 2.81 & 2.96 & 2.34 & 2.40 & 2.21 \\
\hline Growth & $>0$ & 5.87 & 6.97 & 5.16 & 7.95 & 6.45 & 3.25 \\
\hline Timing & $<0$ & 3.11 & 2.97 & 3.07 & 1.73 & 1.52 & 1.93 \\
\hline Momentum & $>0$ & 1.79 & 2.11 & 1.54 & 3.19 & 2.67 & 1.29 \\
\hline Timing & $<0$ & 3.90 & 4.73 & 4.34 & 5.35 & 5.55 & 5.86 \\
\hline
\end{tabular}


Table 5: Proportion tests of fund manager timing skills: investment objective and S\&P style

This table reports the results of proportion tests using the Carhart (1997) four-factor Treynor and Mazuy (1966) model on monthly return data of 3,181 US growth-oriented equity mutual funds from Jan. 1993 to Dec. 2006 broken down by fund objective and S\&P style category. Investment objectives are Equity Aggressive Growth (AG), Equity Growth (GR), Equity Growth-and-Income (GI), and Equity Income-and-Growth (IG). Funds are also separately classified by S\&P Returns-Based Style Analysis into Growth funds (Growth), Blend funds (Blend), and Value funds (Value). Column 1 gives the examined timing skill. Column 2 provides the joint setting of sub-period length and minimum observation number. The subsequent 7 columns provide test results in the form of the significance level of rejecting the null hypothesis that superior performing fund managers of the respective group do not possess the corresponding timing skill. $* * *, * *$, and $*$ represent significance levels of $0.01,0.05$, and 0.1 respectively.

\begin{tabular}{|c|c|c|c|c|c|c|c|c|}
\hline \multirow[b]{2}{*}{ Timing } & \multirow[b]{2}{*}{ Setting } & \multicolumn{4}{|c|}{ Investment Objective } & \multicolumn{3}{|c|}{ S\&P Style } \\
\hline & & $\begin{array}{c}\text { AG } \\
(150)\end{array}$ & $\begin{array}{c}\text { GR } \\
(1,956)\end{array}$ & $\begin{array}{c}\text { GI } \\
(856)\end{array}$ & $\begin{array}{c}\text { IG } \\
\text { (219) }\end{array}$ & $\begin{array}{l}\text { Growth } \\
(1,470)\end{array}$ & $\begin{array}{l}\text { Blend } \\
\text { (428) }\end{array}$ & $\begin{array}{c}\text { Value } \\
(1,283)\end{array}$ \\
\hline $\begin{array}{l}\text { Market } \\
\text { Timing }\end{array}$ & $\begin{array}{c}(3,36) \\
(5,36) \\
(5,60) \\
(9,36) \\
(9,60) \\
(9,108)\end{array}$ & & & & & & & \\
\hline $\begin{array}{c}\text { Size } \\
\text { Timing }\end{array}$ & $\begin{array}{c}(3,36) \\
(5,36) \\
(5,60) \\
(9,36) \\
(9,60) \\
(9,108)\end{array}$ & & & & $\begin{array}{l}* * \\
* *\end{array}$ & & & \\
\hline $\begin{array}{l}\text { Growth } \\
\text { timing }\end{array}$ & $\begin{array}{l}(3,36) \\
(5,36) \\
(5,60) \\
(9,36) \\
(9,60)\end{array}$ & $\begin{array}{l}* * * \\
* * * \\
* * * \\
* * * \\
* * *\end{array}$ & $\begin{array}{l}\text { *** } \\
* * * \\
* * * \\
* * * \\
* * *\end{array}$ & $\begin{array}{c}* * \\
* * \\
* * * \\
* *\end{array}$ & & $\begin{array}{l}* * * \\
* * * \\
* * * \\
* * * \\
* * *\end{array}$ & $\begin{array}{c}* \\
* * * \\
* * * \\
* * *\end{array}$ & $*$ \\
\hline & $(9,108)$ & $* * *$ & $* * *$ & $*$ & & $* * *$ & $*$ & $* *$ \\
\hline $\begin{array}{l}\text { Momentum } \\
\text { timing }\end{array}$ & $\begin{array}{c}(3,36) \\
(5,36) \\
(5,60) \\
(9,36) \\
(9,60) \\
(9,108)\end{array}$ & & & & & & & \\
\hline
\end{tabular}


Table 6: Fund manager growth timing persistence tests

This table reports the results of tests on the persistence of the growth timing abilities of superior performing fund managers based on monthly return data of 3,181 US growth-oriented equity mutual funds from Jan. 1993 to Dec. 2006. Panel A reports the persistence test results for the Carhart (1997) four-factor Treynor and Mazuy (1966) growth timing model (CTM_GT), and panel B the Carhart (1997) four-factor Henriksson and Merton (1981) growth timing model (CHM_GT). Column 1 denotes the decile portfolio rank. Funds with the highest prior 3-year growth timing coefficient $\left(\gamma_{i}\right)$ comprise decile 1 , and funds with the lowest comprise decile 10. Columns 2 and 3 provide the time-series mean and standard deviation of monthly excess returns $\left(r_{i, t}\right)$. The following four columns report values of the intercept $\left(\alpha_{i}\right)$, its bootstrapped p-value, the growth timing coefficient $\left(\gamma_{i}\right)$, and its bootstrapped p-value. The last column reports the adjusted R-square.

\begin{tabular}{|c|c|c|c|c|c|c|c|}
\hline Portfolio & $\begin{array}{c}r_{i, t} \\
(\% \\
/ \text { month })\end{array}$ & $\begin{array}{c}r_{i, t} \\
\text { standard } \\
\text { deviation }\end{array}$ & $\begin{array}{c}\alpha_{i} \\
(\% \\
/ \text { month })\end{array}$ & $\begin{array}{l}\text { p value } \\
\text { of } \alpha_{i}\end{array}$ & $\gamma_{i}$ & $\begin{array}{l}\text { p value } \\
\text { of } \gamma_{i}\end{array}$ & Adj. $\mathrm{R}^{2}$ \\
\hline \multicolumn{8}{|c|}{ Panel A: CTM_GT $r_{i t}=\alpha_{i}+\beta_{i} \cdot R M R F_{t}+s_{i} \cdot S M B_{t}+h_{i} \cdot H M L_{t}+p_{i} \cdot M O M_{t}+\gamma_{j} \cdot H M L_{t}^{2}+\varepsilon_{i t}$} \\
\hline 1 (high) & $0.48 \%$ & $5.59 \%$ & $-0.35 \%$ & 0.022 & 0.344 & 0.001 & 0.923 \\
\hline 2 & $0.11 \%$ & $5.51 \%$ & $-0.31 \%$ & 0.056 & 0.027 & 0.808 & 0.913 \\
\hline 3 & $0.36 \%$ & $5.24 \%$ & $-0.08 \%$ & 0.534 & 0.032 & 0.728 & 0.937 \\
\hline 4 & $0.34 \%$ & $5.15 \%$ & $-0.24 \%$ & 0.084 & 0.129 & 0.169 & 0.931 \\
\hline 5 & $0.35 \%$ & $5.06 \%$ & $-0.14 \%$ & 0.241 & 0.046 & 0.583 & 0.943 \\
\hline 6 & $0.40 \%$ & $4.98 \%$ & $-0.15 \%$ & 0.156 & 0.064 & 0.369 & 0.956 \\
\hline 7 & $0.43 \%$ & $4.55 \%$ & $-0.12 \%$ & 0.181 & 0.044 & 0.468 & 0.960 \\
\hline 8 & $0.55 \%$ & $4.53 \%$ & $-0.20 \%$ & 0.072 & 0.189 & 0.010 & 0.945 \\
\hline 9 & $0.32 \%$ & $4.80 \%$ & $-0.20 \%$ & 0.206 & 0.033 & 0.746 & 0.899 \\
\hline 10 (low) & $0.50 \%$ & $4.86 \%$ & $-0.18 \%$ & 0.201 & 0.048 & 0.621 & 0.924 \\
\hline \multicolumn{8}{|c|}{ Panel B: CHM_GT $r_{i, t}=\alpha_{i}+\beta_{i} \cdot R M R F_{t}+s_{i} \cdot S M B_{t}+h_{i} \cdot H M L_{t}+p_{i} \cdot M O M_{t}+\gamma_{i} \cdot H M L_{t}^{*}+\varepsilon_{i, t}$} \\
\hline 1 (high) & $0.33 \%$ & $5.63 \%$ & $-0.33 \%$ & 0.023 & 0.219 & 0.031 & 0.928 \\
\hline 2 & $0.16 \%$ & $5.00 \%$ & $-0.27 \%$ & 0.051 & 0.012 & 0.899 & 0.934 \\
\hline 3 & $0.37 \%$ & $5.21 \%$ & $-0.25 \%$ & 0.109 & 0.183 & 0.093 & 0.904 \\
\hline 4 & $0.25 \%$ & $5.41 \%$ & $-0.30 \%$ & 0.028 & 0.083 & 0.378 & 0.936 \\
\hline 5 & $0.45 \%$ & $4.81 \%$ & $-0.03 \%$ & 0.756 & 0.031 & 0.664 & 0.954 \\
\hline 6 & $0.35 \%$ & $4.91 \%$ & $-0.21 \%$ & 0.073 & 0.048 & 0.550 & 0.944 \\
\hline 7 & $0.43 \%$ & $4.74 \%$ & $-0.09 \%$ & 0.481 & 0.068 & 0.423 & 0.928 \\
\hline 8 & $0.29 \%$ & $4.49 \%$ & $-0.32 \%$ & 0.003 & 0.101 & 0.160 & 0.948 \\
\hline 9 & $0.47 \%$ & $4.60 \%$ & $-0.16 \%$ & 0.212 & 0.141 & 0.103 & 0.928 \\
\hline 10 (low) & $0.62 \%$ & $4.94 \%$ & $-0.11 \%$ & 0.387 & 0.109 & 0.197 & 0.936 \\
\hline
\end{tabular}

